\title{
PEMBUATAN HARDBOARD DARI SERAT ALTERNATIF MENGGUNAKAN LIGNIN ALAMINYA DAN TANIN FORMALDEHIDA SEBAGAI PEREKAT
}

\author{
Dian Anggraini Indrawan ${ }^{1}$, Han Roliadi, Rossi Margareth Tampubolon, Mohamad Iqbal, Lisna Efiyanti \\ Pusat Penelitian dan Pengembangan Keteknikan Kehutanan dan Pengolahan Hasil Hutan \\ Jalan Gunung Batu No. 5, Bogor 16610 \\ ${ }^{1}$ elisabeth_dian@yahoo.com
}

Diterima : 9 Februari 2015, Revisi akhir : 4 Mei 2015, Disetujui terbit : 22 Mei 2015

\section{MANUFACTURE OF HARDBOARD FROM ALTERNATIVE FIBER MATERIALS USING ITS LIGNIN AND TANNIN FORMALDEHYDE AS BINDER}

\begin{abstract}
The most numerous uses of hardboard are for sound-deadening barrier, insulation wall, furniture, part of electronic appliances, and vehicle interior.Nowadays, in Indonesia the availability of natural-forest woods (the conventional ligno-cellulosic fibrous raw material) for fiberboard manufacture becomes limited and scarce. Thus, non-wood alternative fibers should be considered as raw material for fiber board. In this study, experiment was done using alternative fibers which were Saccharum spontaneum grasses (SSG), empty oil-palm bunches (EOPB), and bamboo. The pulping and mat forming employed consecutively an open-hot soda semi-chemical process and wet-forming process. The additives for hardboard forming comprised wax emulsion and tannin formaldehyde (TF) adhesive. Alkali consumption in the pulping of alternative fibers (SSG, EOPB, and bamboo) for hardboard ranged about 88-99\% (regarded as quite high, near 100\%). SSG was the most prospective for hardboard, followed by consecutively EOPB and bamboo. Also, physical-strength properties of hardboard from SSG satisfied the JIS and ISO requirement the most. The prospective results of fiberboard manufacture from the alternative fiber materials will expectedly lessen the dependency on naturalforest woods thereby sustaining the natural resources, and alleviating environment concerns. The high alkali consumption and wet-forming implementation hinted that this fiberboard-manufacturing experiment is more suitable for small-medium scale endeavor (SME).
\end{abstract}

Keywords: hardboard, alternative ligno-cellulosic fiber materials, prospective results, sustaining natural resources, small-to-medium scale endeavor (SME)

\begin{abstract}
ABSTRAK
Hardboard banyak digunakan antara lain untuk bahan peredam suara, dinding penyekat, mebel, bagian dari peralatan elektronik dan interior kendaraan. Di Indonesia, ketersediaan kayu hutan alam (bahan baku serat berligno-selulosa konvensional) untuk pembuatan papan serat di Indonesia semakin terbatas dan langka. Oleh karena itu bahan serat alternatif harus dipertimbangkan sebagai bahan baku papan serat. Dalam penelitian ini dilakukan percobaan pembuatan papan serat (hardboard) dari bahan serat alternatif, yaitu rumput gelagah (RG), tandan kosong kelapa sawit (TKKS) dan bambu. Pengolahan pulp (pulping) dan pembentukan lembaran untuk papan serat menggunakan proses semi-kimia soda panas terbuka dengan pembentukan cara basah (wet process). Bahan aditif yang digunakan adalah emulsi lilin dan perekat tanin formaldehida (TF) Konsumsi alkali pada pulping adalah 88-99\% (dianggap cukup tinggi, mendekati 100\%). RG paling berprospek untuk hardboard diikuti oleh TKKS dan bambu, dan sifat fisik-kekuatan hardboard dari RG paling banyak memenuhi persyaratan JIS dan ISO. Hasil prospektif pemanfaatan serat alternatif untuk papan serat diharapkan bermanfaat mengurangi ketergantungan pada kayu hutan alam sehingga ikut melestarikan sumber daya alam. Tingginya konsumsi alkali dan penerapan cara basah berindikasi bahwa pengolahan papan serat ini lebih sesuai untuk usaha kecil menengah (UKM).
\end{abstract}

Kata kunci: hardboard, bahan baku serat alternatif, hasil prospektif, melestarikan sumber daya alam, usaha kecil menengah (UKM) 


\section{PENDAHULUAN}

Papan serat adalah panel homogen yang terbuat dari serat lignoselulosa yang dikombinasikan dengan resin sintetis atau perekat alami (seperti kasein dari susu sapi, darah binatang, protein kedelai, dan pati tumbuhan) yang kemudian disatukan di bawah menggunakan tekanan dan panas (ANSI standards, 1994). Papan serat termasuk kategori produk rekonstitusi kayu atau serat berlignoselulosa lain (antara lain merang padi, bambu, ampas tebu, tandan kosong kelapa sawit, dan limbah pertanian/ perkebunan). Pembuatan papan serat dengan proses kering menjadi terbatas karena prosesnya mengkonsumsi lebih banyak bahan perekat/ pengikat (Suchsland dan Woodson, 1986). Usahausaha untuk memproduksi papan serat hasil proses kering tanpa pengikat resin umumnya tidak berhasil (Mancera dkk., 2011). Sebaliknya pada pembuatan papan serat dengan proses basah, bahan aditif berupa perekat sebenarnya tidak selalu diperlukan, karena lignin yang terkandung dalam serat dapat berperan sebagai perekat/ pengikat antar serat. Menurut Saputro dkk. (2012), perekat alami (lignin dan hemiselulosa) yang terdapat dalam biomassa dapat lebih diefektifkan dengan cara menaikkan suhu. Lignin mempunyai sifat amorf termoplastis yang dapat diefektifkan melalui tekanan (pengempaan) yang rendah dan suhu sekitar $600^{\circ} \mathrm{C}-900^{\circ} \mathrm{C}$. Pada tanaman, lignin berguna dalam kayu seperti lem atau semen yang mengikat sel-sel lain dalam satu kesatuan, sehingga bisa menambah sifat kekuatan kayu agar kokoh dan berdiri tegak (Wibisono dkk., 2011). Di lain hal, menurut Mansouri dan Salvado dalam Hayati (2011) sebagian papan serat menggunakan perekat sintetis berbahan dasar minyak bumi yang kurang bersahabat dengan lingkungan dan bersifat tidak terbarukan, diantaranya adalah fenol formaldehida. Bahan dasar perekat lignin yang terbarukan di mana didalamnya juga terdapat inti fenol (Sjostrom, 2002) diharapkan sangat sesuai untuk dikembangan sebagai bahan dasar perekat ramah lingkungan.

Selain mengandalkan lignin, dan agar kekuatan papan serat proses basah lebih tinggi, pada pembuatan papan serat dapat juga ditambahkan tanin formaldehida sebagai perekat alami yang ramah lingkungan, karena di dalam tanin juga terdapat inti fenol (Santoso, 2011). Bertaud dkk. (2012) menyatakan bahwa untuk mengurangi emisi formaldehida dari panel kayu dan mengembangkan perekat alami yang ramah lingkungan, polimer alami berinti fenol, yaitu tanin dan lignin telah diteliti sebagai substitusi dari perekat berbahan dasar minyak bumi untuk perekat bahan panel kayu atau serat berlignoselulosa lain. Di samping penggunaan bahan aditif yang berperan sebagai perekat (pengikat) untuk panel tersebut, aditif berfungsi lain juga bisa digunakan (a.l. emulsi lilin, zat warna, pengawet, dan fire retardant) dapat juga ditambahkan guna memperbaiki sifat papan serat seperti ketahanan air, keawetan, warna menarik, dan ketahanan api (Suchlands dan Woodson, 1986).

Pembuatan papan serat melibatkan dua tahapan utama, yaitu pengolahan menjadi pulp (pulping) dan pembentukan lembaran papan serat. Proses pulping yang umum adalah cara mekanis dan semi-kimia, termasuk modifikasi dua cara tersebut (Smook, 2002). Pembentukan lembaran papan serat ada dua macam, yaitu cara basah dan cara kering. Cara basah menggunakan air untuk merubah pulp menjadi lembaran papan serat, sedangkan cara kering menggunakan media udara.

Berdasarkan kerapatan, terdapat 3 macam papan serat, yaitu kerapatan rendah $(<0,40 \mathrm{~g} /$ $\mathrm{cm}^{3}=$ papan isolasi), sedang $\left(0,40-0,80 \mathrm{~g} / \mathrm{cm}^{3}\right.$ $=$ MDF), dan tinggi $\left(>0,80 \mathrm{~g} / \mathrm{cm}^{3}=\right.$ hardboard $)$. Papan MDF dan hardboard banyak digunakan untuk bahan peredam suara, dinding penyekat, mebel, bagian peralatan elektronik, interior kendaraan, dan konstruksi ringan hingga sedang (Smook, 2002).

Permintaan papan serat di Indonesia cenderung meningkat, ekspor dan impor selama periode 2008-2012, yaitu berturut-turut 68.4116,2 ribu ton dan 195,8-249,7 ribu ton (Badan Pusat Statistik, 2013). Nilai impor yang lebih besar dari ekspor mengindikasikan bahwa produksi papan serat Indonesia saat ini belum dapat memenuhi kebutuhan domestik. Di Indonesia, kayu hutan alam tropis merupakan bahan baku konvensional untuk papan serat, yang potensinya semakin menurun. Menurut Forest Watch Indonesia (2013), pemanfaatan hutan Indonesia khususnya untuk memenuhi kebutuhan pasar telah berdampak pada berkurangnya luas tutupan hutan (deforestasi). Pada periode 20092013, laju deforestasi rata-rata adalah 1,13 juta hektar per tahun. Laju deforestasi yang tinggi ini berdampak pada peningkatan emisi gas rumah kaca, kerawanan bencana, hilangnya satwa liar 
dan habitatnya, dan konflik berbagai pemangku kepentingan. Dan menurut Syamsu dkk. (2014) laju deforestasi ini diperkirakan akan semakin meningkat seiring dengan meningkatnya permintaan terhadap kayu dan produk-produk berbahan baku kayu. Untuk mengurangi ketergantungan pada kayu hutan alam, perlu dicari serat alternatif yang potensinya berlimpah dan belum banyak dimanfaatkan seperti rumput gelagah, bambu dan tandan kosong kelapa sawit (TKKS).

Rumput gelagah dan TKKS selama ini belum terlalu banyak dimanfaatkan untuk papan serat/ hardboard, dimana menurut Narwin (2012), rumput gelagah adalah jenis tanaman yang tumbuh secara liar dihutan. Sekilas nampak rumput ini tidak begitu bermanfaat karena hanya mengganggu tanaman masyarakat sehingga petani selalu membabatnya ketika melakukan pembersihan lahan tujuannya agar tidak mengganggu tanaman yang ada dan hanya dimanfaatkan untuk pakan ternak dan pembuatan sapu.. Hal yang menarik adalah rumput gelagah merupakan tanaman menahun (tumbuh sepanjang tahun), tumbuh bergerombol, dapat tumbuh baik di daerah tropis maupun non-tropis. Gelagah dapat berkembang biak secara generatif (melalui biji) atau secara vegetatif (melalui stek batang). Pertumbuhan akar gelagah dapat menembus jauh ke dalam tanah, oleh karenanya dapat mencegah erosi pada tanah berpasir dan berkelerengan agak curam. Pertumbuhan gelagah yang cepat dan bergerombol, maka kalau dibiarkan dapat mengambil alih (invasive) pertumbuhan tanaman lain (Anonim, 2012b).

Di lainhal, dengan luas areal perkebunan kelapa sawit di Indonesia mencapai 7.099.388 ha, saat ini pemanfaatan serat TKKS yaitu untuk pupuk organik, bahan baku pembuatan kertas, briket, dan umumnya baru sampai pada pemanfaatan serat sebagai bahan pengisi suatu medium seperti pengisi rongga jok mobil dan kasur.produk utama kelapa sawit yang dimanfaatkan adalah tandan buahnya yang menghasilkan minyak, dan setelah proses pengolahan, tersisa Tandan Kosong Kelapa Sawit (TKKS) sebagai produk sampingan (Wardani, 2014).

Di Indonesia terdapat 172 spesies bambu asli nusantara dan 36 spesies yang diintroduksi dari luar negeri. Dunia memiliki 37 juta hektar hutan bambu natural ataupun budidaya yang setara dengan satu persen luasan hutan dunia. Dari jumlah itu, lima persen di antaranya terdapat di Indonesia sementara China memiliki 14 persen, dan India yang terluas, yaitu 30 persen. Dan menurut data Kementerian Kehutanan RI, pendapatan dari bambu pada tahun 2010 sampai 2011 ada peningkatan 24\% (The President Post, 2013). Ekspor bambu di Indonesia pada tahun 2012 sebanyak 121,2 juta dolar. Kondisi ini memperlihatkan masih adanya peluang pasar untuk bambu maupun produk bambu (Berita WMC, 2012 dalam Alamsyah dkk., 2013). Bambu dikenal memiliki sifat-sifat yang sangat menguntungkan untuk dimanfaatkan karena, batangnya kuat, ulet, lurus, rata, keras, mudah dibelah, mudah dibentuk dan mudah dikerjakan serta ringan sehingga mudah diangkut. Selain itu, bambu juga relatif murah dibandingkan dengan bahan bangunan lain seperti kayu (Purwito dkk., 2012).

Dengan adanya sumber bahan baku yang belum banyak dimanfaatkan untuk papan serat seperti rumput gelagah dan TKKS, serta bambu yang memiliki keunggulan sebagai pengganti kayu, maka dilakukan percobaan pembuatan papan serat dari serat alternatif yaitu rumput gelagah, tandan kosong kelapa sawit, dan bambu yang menggunakan perekat alami yaitu tanin formaldehida (TF) dan lignin. TKKS, rumput gelagah, dan bambu merupakan bahan serat berligno-selulosa seperti halnya kayu (bahan baku serat konvensional untuk papan serat/harboard). Dengan demikian pemanfaatan ketiga macam serat alternatif tersebut diharapkan layak teknis untuk hardboard dengan sifat yang memuaskan dan memenuhi persyaratan standar.

\section{BAHAN DAN METODE}

\section{Persiapan dan Metodologi}

Pembuatan hardboard menggunakan bahan serat rumput gelagah (RG), tandan kosong kelapa sawit (TKKS), dan bambu dengan cara basah (wet process) (Indrawan dkk., 2013a). Contoh RG (Saccharum spotaneum) diambil dari Jawa Tengah dan Jawa Timur; contoh TKKS (Elaeis guineensis), dan bambu jenis andong (Gigantochloa psedoarundinaceae) dari Provinsi Banten dan Jawa Barat. Sebelum masing-masing bahan serat (RG, TKKS, dan bambu) diolah (dimasak) menjadi pulp, dilakukan pemeriksaan sifat dasarnya, yang mencakup kerapatan, komposisi kimia, dan dimensi serat berikut nilai turunannya, menurut standard TAPPI (2007). 
Pemasakan masing-masing bahan pada serat (RG, TKKS, dan bambu) menggunakan proses semikimia soda panas terbuka. Konsentrasi alkali dibuat 2 variasi yaitu $9,0 \%$ dan $10,5 \%$, dengan nilai banding bahan serat terhadap larutan pemasak 1:8 (b/v), pada suhu $100^{\circ} \mathrm{C}$ selama 3 jam. Selesai pemasakan, serpih lunak dipisahkan dari sisa larutan pemasak (spent liquor). Pada sisa larutan pemasak dilakukan pemeriksaan sisa akali guna penetapan konsumsi alkali (TAPPI, 2007). Serpih lunak (masing-masing dari RG, TKKS, dan bambu) selanjutnya digiling secara terpisah dalam hollander beater pada konsistensi 3-4\%, menjadi serat terpisah (pulp). Penggilingan dihentikan ketika derajat kehalusan pulp mencapai 600-700 mL CSF (TAPPI, 2007), dan waktu giling dicatat. Pulp yang diperoleh kemudian ditentukan rendemennya.

Ketiga macam pulp (dari RG, TKKS, bambu) dicampur menjadi 7 macam proporsi/komposisi yaitu: $100 \%+0 \%+0 \%, 0 \%+100 \%+0 \%$, $0 \%+0 \%+100 \%, 50 \%+50 \%+0 \%, 50 \%+0 \%+50 \%$, $0 \%+50 \%+50 \%, 33,33 \%+33,33 \%+33,33 \%$. Masing-masing proporsi tersebut secara terpisah diberi bahan aditif (tawas/alum 3\%, emulsi lilin 5\%, dan perekat $\mathrm{TF} 4 \%$ ); dan hasilnya siap dibentuk menjadi lembaran hardboard. Masing-masing dari ketujuh proporsi tersebut juga disiapkan tetapi tidak ditambahkan bahan aditif, dan selanjutnya juga dibentuk menjadi harboard (sebagai kontrol). Pembentukan lembaran hardboard dari masing-masing proporsi tersebut (dengan aditif atau tanpa aditif/ kontrol) dilakukan dengan cara basah (berukuran $30 \mathrm{~cm}$ x $30 \mathrm{~cm} \times 0,5 \mathrm{~cm}$, dengan target kerapatan $1 \mathrm{~kg} / \mathrm{cm}^{2}$ ). Pembentukan cara basah tersebut dilakukan menggunakan fiberboard-mat former (deckle box), dilanjutkan dengan pengempaan dingin dan pengempaan panas (pada suhu $175^{\circ} \mathrm{C}$, tekanan $30 \mathrm{~kg} / \mathrm{cm}^{2}$, selama 10 menit). Hardboard yang terbentuk dikondisikan selama 24 jam, dan siap dilakukan pengujian sifat fisis/kekuatannya. Pengujian tersebut (mencakup kerapatan, kadar air, pengembangan tebal, penyerapan air, MOR, MOE, keteguhan rekat internal (JIS, 2003); dan daya hantar panas dan ketahanan panas (ISO (2013). Selanjutnya, untuk menelaah bahan serat mana secara individu dan proporsi campuran mana yang paling berprospek hingga paling tidak-berprospek untuk pembuatan hardboard berdasarkan keseluruhan hasil pengujian sifat fisis/kekuatan hardboard, dilakukan pencermatan dengan analisis diskriminan (SAS, 2007).

\section{Pencermatan Skala Nano}

Untuk melengkapi atau sebagai informasi tambahan hasil pengujian secara konvensional (sifat dasar bahan serat rumput gelagah, TKKS, bambu; sifat pengolahan pulp, dan sifat hardboard), dilakukan pencermatan berskala nano menggunakan alat $X$-ray diffraction.

\section{HASIL DAN PEMBAHASAN}

\section{Sifat Dasar Bahan Serat}

Hasil pemeriksaan sifat dasar bahan tersebut (berat jenis/kerapatan, komposisi kimia, dan dimensi serat/nilai turunannya), disajikan pada Tabel 1 dan Tabel 2.

\section{Kadar Air, Berat Jenis, dan Komposisi Kimia}

Berat jenis rumput gelagah paling rendah, sedangkan yang paling besar adalah bambu (Tabel 1). Diduga kuat dalam rumput gelagah terdapat lebih banyak porsi bahan bukan serat (jaringan parenkhim), dan hal ini terkait dengan tingginya kelarutan dalam alkohol benzen, air dingin, air panas, dan $\mathrm{NaOH} 1 \%$. Fenomena serupa juga menjelaskan lebih rendahnya berat jenis TKKS dari pada bambu (Meyer, dkk., 1985; Saupe, 2011). Kadar air tertinggi adalah pada rumput gelagah, diikuti oleh TKKS dan bambu. Ini berindikasi pada rumput gelagah dan TKKS terdapat bahan ekstraktif yang bersifat hidrofilik, sebagaimana terkait dengan tingginya kelarutan dalam $\mathrm{NaOH}$ 1\% dan air dingin/panas. Paling tingginya kelarutan TKKS dalam alkali $(\mathrm{NaOH})$ $1 \%$ juga berindikasi adanya bahan ekstraktif kurang polar atau hidrofobik (minyak/lemak) yang kemudian terlarut akibat reaksi penyabunan dengan alkali (Browning, 1967). Kadar air dan berat jenis bahan serat yang tinggi tidak dikehendaki sebab lebih mudah terdegradasi (hidrolisis) dan meningkatkan bobotnya, sehingga memerlukan lebih banyak energi pada tahapan pengerjaan selanjutnya seperti pemotongan, penyerpihan, dan pemasakan (Casey, 1980).

Kadar abu tertinggi terdapat pada rumput gelagah, sedangkan kadar silika tertinggi pada TKKS, dan bambu menunjukkan kadar abu/ silika terendah. Kadar abu dan silika tinggi tak dikehendaki karena cepat mempertumpul peralatan logam, menggangu ikatan/anyaman antara serat selama pembentukan lembaran 
Tabel 1. Kadar Air, Berat Jenis, dan Komposisi Kimia Bahan Serat Rumput Gelagah, TKKS, dan $\mathrm{Bambu}^{*}$

\begin{tabular}{clccc}
\hline No & \multicolumn{1}{c}{ Parameter sifat dasar } & TKKS & Bambu & RG \\
\hline 1. & Kadar air (\%) & 10,17 & 7,74 & 12,14 \\
2. & Berat jenis/kerapatan $\left(\mathrm{g} / \mathrm{cm}^{3}\right)$ & 0,512 & 0,638 & 0,340 \\
3. & Kadar abu (\%) & 4,37 & 2,40 & 12,19 \\
4. & Kadar silika (\%) & 0,992 & 0,017 & 0,081 \\
5. & Kadar lignin (\%) & 20,71 & 33,23 & 21,90 \\
6. & Kadar selulosa (\%) & 40,83 & 56,74 & 36,02 \\
7. & Kadar pentosan (\%) & 22,44 & 18,91 & 19,92 \\
8. & Kelarutan dalam alkohol benzene 1:2 (\%) & 5,35 & 4,81 & 8,49 \\
9. & Kelarutan dalam air dingin (\%) & 6,88 & 2,54 & 12,54 \\
10. & Kelarutan dalam air panas (\%) & 8,92 & 4,32 & 15,12 \\
11. & Kelarutan dalam NaOH 1\% (\%) & 19,90 & 17,11 & 18,10 \\
\hline
\end{tabular}

*) Nilai rata-rata; $R G=$ rumput gelagah; $T K K S=$ tandan kosong kelapa sawit

Tabel 2. Dimensi Serat dan Nilai Turunannya untuk Rumput Gelagah, TKKS, dan Bambu*)

\begin{tabular}{clccc}
\hline No & \multicolumn{1}{c}{ Parameter sifat dasar } & TKKS & Bambu & RG \\
\hline A & Dimensi serat & & & \\
1. & Panjang serat $(\mathrm{L}), \mu \mathrm{m}$ & 1285,15 & 3655,22 & 1518,88 \\
2. & Diameter serat $(\mathrm{d}), \mu \mathrm{m}$ & 21,64 & 27,71 & 19,52 \\
3. & Diameter lumen $(\mathrm{l}), \mu \mathrm{m}$ & 14,45 & 16,63 & 12,93 \\
4. & Tebal Dinding Serat $(\mathrm{w}), \mu \mathrm{m}$ & 3,60 & 5,54 & 3,29 \\
B & Nilai turunan dimensi serat & & & \\
5. & Daya tenun serat $(\mathrm{L} / \mathrm{d})$ & 59,07 & 121,28 & 82,26 \\
6. & Bilangan Muhlstep [100 $\left.\left.\left(\mathrm{d}^{2}-\mathrm{l}^{2}\right) / \mathrm{d}^{2}\right]^{*} 100\right], \%$ & 56 & 63 & 57 \\
7. & Koefisien Kelemasan Serat $(\mathrm{l} / \mathrm{d})$ & 0,66 & 0,60 & 0,65 \\
8. & Bilangan Runkel $(2 \mathrm{w} / \mathrm{l})$ & 0,51 & 0,71 & 0,54 \\
9. & Kekakuan Serat $(\mathrm{w} / \mathrm{d})$ & 0,17 & 0,20 & 0,17 \\
\hline
\end{tabular}

"Nilai rata-rata; $R G=$ rumput gelagah; $T K K S=$ tandan kodong kelapa sawit

papan serat sehingga berakibat negatif terhadap sifat fisis dan mekanis papan tersebut (Suchsland dan Woodson, 1986; Roliadi dkk., 2012). Kadar selulosa tertinggi adalah pada bambu, diikuti oleh TKKS dan rumput gelagah. Bambu menunjukkan kadar lignin tertinggi, sedangkan antara TKKS dan rumput gelagah tidak berbeda jauh. Kadar pentosan tertinggi pada TKKS, sedangkan antara bambu dan rumput gelagah tidak berbeda jauh. Kadar selulosa, lignin, dan pentosan tinggi dikehendaki untuk papan serat. Selulosa merupakan salah satu penyusun bahan serat, sedangkan lignin berperan sebagai pengikat antar serat pada papan serat dan pentosan memudahkan proses penggilingan serat pulp sehingga tak mudah rusak pada perlakukan mekanis (Casey, 1980; Smook, 2002). Berdasarkan keseluruhan sifat dasar tersebut, bambu berindikasi paling berprospek untuk hardboard dibandingkan TKKS (urutan prospek kedua) dan rumput gelagah (prospek terendah).

\section{Dimensi Serat dan Nilai Turunannya}

Data dimensi serat dan nilai turunan dimensi serat dari ketiga macam bahan serat (TKKS, RG, dan bambu) disajikan pada Tabel 2 . Hasil pencermatan menunjukkan bahwa serat (bentuk bahan) baku berdimensi terpanjang dan berdiameter terbesar adalah bambu, sedangkan serat terpendek pada TKKS dan diameter terkecil pada rumput gelagah (Tabel 2). Diameter lumen terbesar dan dinding serat paling tebal adalah pada bambu, diikuti oleh TKKS dan rumput gelagah. Serat bambu menunjukkan daya tenun tertinggi, diikuti oleh rumput gelagah dan TKKS. 
Bilangan Muhlstep, bilangan Runkel, dan koefisien kekakuan tertinggi adalah pada bambu, sedangkan antara TKKS dan rumput gelagah tidak berbeda nyata. Dalam hal koefisien fleksibilitas serat, nilai terendah pada bambu, sedangkan tertinggi pada TKKS dan rumput gelagah.

Serat yang panjang lebih dikehendaki untuk papan serat (termasuk hardboard) karena menungkinkan jalinan dan anyaman serat lebih intensif selama pembentukan lembaran papan tersebut. Dinding serat tipis, diameter serat dan lumen besar, daya tenun dan kelemasan serat tinggi; dan bilangan Runkel, koefisien kekakuan, dan bilangan Muhlstep rendah juga dikehendaki, karena semua hal tersebut terindikasi berkaitan erat dengan sifat menggepeng, fleksibilitas, dan anyaman serat, sehingga berpengaruh positif terhadap kualitas produk pulp termasuk hardboard (Silitonga dkk., 1972; Apriani, 2010). Berdasarkan pencermatan keseluruhan dimensi serat dan nilai turunannya, ternyata prospek bambu dan rumput gelagah untuk papan serat (hardboard) hampir sama tingginya (Tanel 2), sedangkan prospek TKKS sedikit di bawah kedua macam bahan serat tersebut.

\section{Sifat Pengolahan Pulp}

Hasil pengolahan pulp masing-masing ketiga macam bahan serat (Tabel 3) menunjukkan bahwa pada konsentrasi alkali baik $9,0 \%$ ataupun $10,5 \%$, rendemen pulp tertinggi adalah dari bambu, diikuti oleh TKKS, dan RG. Diduga ini terjadi karena diindikasikan bambu memiliki kadar lignin tertinggi (Tabel 1). Peningkatan konsentrasi alkali cenderung menurunkan rendemen pulp, yang diduga terkait dengan lebih banyaknya lignin terlarut secara parsial (Smook, 2002). Rendemen pulp yang dihasilkan dari suatu proses pemasakan sangat berkaitan dengan banyaknya bahan kimia pemasak yang berpenetrasi kedalam struktur kayu, sehingga memungkinkan terjadinya reaksi antara bahan kimia pemasak dengan komponen kimia kayu yang semakin cepat, pada konsentrasi akali lebih tinggi. Tingginya rendemen pada konsentrasi alkali lebih rendah dapat terjadi dikarenakan proses pemisahan serat dan pelarutan lignin belum sempurna. Sebaliknya rendemen rendah dapat terjadi karena semakin banyak komponen kimia yang terdegradasi yaitu pelarutan lignin dan pengurangan polisakarida dalam pulp, pada konsentrasi alkali lebih tinggi (Laksono, 2008). Pada pembentukan papan serat proses basah, lignin diharapkan masih tersisa karena berfungsi sebagai perekat.

Nilai rendemen terendah yaitu pulp dari RG, diduga karena tingginya porsi bahan bukan serat yang diindikasikan dengan tingginya kelarutan dalam alkohol benzen, air dingin/panas, dan $\mathrm{NaOH} 1 \%$ (Tabel 1). Menurut Gumardes (2003) dalam Laksono (2008), semakin kecil nilai kelarutan pulp dalam $\mathrm{NaOH} 1 \%$ maka dapat diduga bahwa kerusakan yang terjadi pada selulosa semakin kecil dan semakin sedikit komponen kimia yang terlarut.

Konsumsi alkali merupakan angka yang menunjukkan presentase alkali yang dikonsumsi oleh bahan baku selama proses pemasakan (Syamsu dkk., 2014). Konsumsi alkali tertinggi

Tabel 3. Sifat Pengolahan Pulp Rumput Gelagah, TKKS, dan Bambu*)

\begin{tabular}{llcccccc}
\hline No & \multicolumn{3}{c}{ Rincian Terkait } \\
\hline 1 & Macam bahan serat & \multicolumn{2}{c}{ TKKS } & \multicolumn{2}{c}{ Bambu } & \multicolumn{2}{c}{ Rumput Gelagah } \\
\cline { 2 - 7 } 2 & Konsentrasi alkali, \% & 9,0 & 10,5 & 9,0 & 10,5 & 9,0 & 10,5 \\
3 & Sifat Pengolahan pulp: & & & & & & \\
& -Rendemen pulp, \% & 75,26 & 65,55 & 76,98 & 78,87 & 60,53 & 61,49 \\
& -Konsumsi alkali, \% 1) & 8,94 & 9,53 & 7,95 & 8,98 & 8,92 & 10,06 \\
& -Konsumsi alkali, \% 2) & 99,33 & 90,76 & 88,33 & 85,52 & 99,11 & 95,80 \\
& -Derajat kehalusan pulp, ml CSF & 735 & 725 & 735 & 725 & 735 & 705 \\
& -Waktu giling mencapai 650-700 & 65 & 60 & 74 & 70 & 70 & 65 \\
& ml CSF, menit & & & & & & \\
\end{tabular}

"Nilai rata-rata; TKKS = tandan kosong kelapa sawit; ${ }^{1}$ Berdasarkan berat serat kering oven; ${ }^{2)}$ Berdasarkan konsentrasi alkali awal 
adalah pada pemasakan (pulping) rumput gelagah, diikuti oleh TKKS dan bambu. Fenomena ini terkait dengan tingginya porsi bahan bukan serat pada rumput tersebut; sedangkan pada bambu, porsi bahan bukan seratnya paling rendah (Tabel 1).Konsumsi alkali yang juga tinggi pada pulping TKKS, mengindikasikan adanya sisa minyak/ lemak di dalamnya. Selanjutnya,peningkatan konsentrasi alkali meningkatkan pula konsumsinya; dan ini sesuai dengan fenomena kimia kinetis (Indrawan dkk., 2013). Menurut Laksono (2008) peningkatan konsumsi alkali ini terjadi sebagai akibat dari semakin tingginya reaksi kimia antara komponen kimia kayu dengan larutan pemasak, terutama reaksi delignifikasi dan degradasi polisakarida (hemiselulosa).

Derajat kehalusan awal pulp (mL CSF) pada konsentrasi alkali 9,0\% terindikasi tidak saling berbeda antara 3 macam bahan serat (TKKS, bambu, dan rumput gelagah). Pada konsentrasi $10,5 \%$, derajat kehalusan awal pulp terendah adalah dari RG; sedangkan antara TKKS dan bambu, derajat kehalusan tersebut tak terlalu berbeda. Makin rendah derajat kehalusan pulp mengindikasikan bahwa tingkat defiberisasi (pemisahan) serat makin intensif. Tingginya porsi bahan bukan serat pada RG (indikasi sifat hidrofilik) diduga terkait dengan semakin mudahnya proses defiberisasi serat pulpnya (Smook, 2002). Lebih lanjut, peningkatan konsentrasi alkali menurunkan derajat kehalusan pulp (memudahkan penggilingan); dan ini terkait dengan semakin intensifnya proses delignifikasi parsial (sifat lignin kurang hidrofilik).

Waktu giling mencapai 600-700 mL CSF semakin singkat dengan meningkatnya konsentrasi alkali. Delignifikasi yang semakin intensif, berakibat pula lebih banyak senyawa pentosan yang terekspos pada permukaan serat; dan pentosan banyak berperan sebagai pelumas (lubricant) pada proses penggilingan pulp (Smook, 2002).

Serat TKKS menunjukkan waktu giling tersingkat yang diduga terkait dengan kadar pentosannya yang paling tinggi (Tabel 2). Pada pengolahan pulp semikimia untuk papan serat (termasuk tipe hardboard), dikehendaki rendemen pulp tinggi, sedangkan konsumsi alkali, derajat kehalusan awal pulp, dan waktu giling pulp yang rendah (singkat). Ini terkait dengan kapasitas produksi, pemakaian bahan kimia, dan energi (panas atau listrik). Berdasarkan anggapan tersebut, maka terindikasi bahwa pulp bambu pada konsentrasi akali 10,5\% paling berpotensi untuk papan serat, sedangkan potensi TKKS dan rumput gelagah pada urutan kedua dan ketiga (juga pada konsentrasi alkali 10,5\%)

\section{Sifat Fisik dan Mekanik Hardboard}

Hasil pencermatan data sifat fisik dan kekuatan hardboard dapat dilihat pada Tabel 4. Sifat hardboard yang dikehendaki konsumen adalah kadar air, penyerapan air, pengembangan tebal, daya hantar panas yang rendah; sementara kerapatan, sifat kekuatan (MOE, MOR, IB), dan ketahanan panas tinggi. Anggapan tersebut diterapkan sebagai masukkan pada telaahan dengan analisis diskriminan

Dari hasil penerapan tersebut persamaan persamaan yaitu Y-discr $=\sum$ bi*Yi $=$ +48,11241Y1 (kerapatan) -24,12352 Y2 (kadar

Tabel 4. Sifat Fisik Mekanik Hardboard ${ }^{*}$

\begin{tabular}{clc}
\hline \multirow{2}{*}{ No. } & \multicolumn{1}{c}{$\begin{array}{c}\text { Parameter Sifat Fisik, Mekanik dan Emisi } \\
\text { Formaldehida MDF }\end{array}$} & Selang Nilai \\
\hline 1. & Kadar air $(\%)$ Basis Kering & $3,071-10,804$ \\
2. & Kerapatan $\left(\mathrm{g} / \mathrm{cm}^{3}\right)$ & $0,7705-1,0635$ \\
3. & Keteguhan lentur $/ \mathrm{MOE}\left(\mathrm{kg} / \mathrm{cm}^{2}\right)$ & $16.539-45.990$ \\
4. & Keteguhan patah/MOR $\left(\mathrm{kg} / \mathrm{cm}^{2}\right)$ & $152,38-449,68$ \\
5. & Keteguhan internal/IB $\left(\mathrm{kg} / \mathrm{cm}^{2}\right)$ & $1,60-7,01$ \\
6. & Penyerapan air $(\%)$ & $61,776-118,557$ \\
7. & Pengembangan tebal $(\%)$ & $12,205-57,988$ \\
8. & Daya hantar panas $\left(\mathrm{w}^{-1} \cdot \mathrm{m}^{-1}\right)$ & $0,055897-0,088915$ \\
9. & Ketahanan panas $\left(\mathrm{m}^{2} \cdot \mathrm{k}^{-1}\right)$ & $0,058998-0,116644$ \\
\hline
\end{tabular}

Keterangan: * Nilai rata-rata 
air) +58.91632 Y3 (MOE) +67,21982 Y4 (MOR) $+43,99751$ Y5 (IB) -9,61326 Y6 (penyerapan air) $-24,15673$ Y7 (pengembangan tebal) $-33,12543$ Y8 (daya hantar panas) $+26,13452$ Y9 (ketahanan panas); dimana nilai Yi juga merupakan nilai sifat hardboard yang sudah dibakukan (standardized) menjadi tanpa satuan (Lampiran 1). Nilai mutu ( $\mathrm{Y}$ diskr) yang terbesar dari persamaan tersebut pada kombinasi perlakuan tertentu (proporsi campuran RG + TKKS + bambu, pada konsentrasi alkali 9,0\% terhadap 10,5\%, dan menggunakan aditif/perekat TF terhadap kontrol/tanpa-perekat) mengindikasikan bahwa proporsi tersebut paling prospektif untuk pembuatan hardboard; sebaliknya pada nilai Y diskr terendah menunjukkan kombinasi tersebut paling-tidak-prospektif. Persamaan diskriminan tersebut dianggap memadai (representatif) karena memiliki nilai koefisien determinasi kanonik nyata $\left(\mathrm{R}^{2}=0,912^{* *}\right)$. Selanjutnya, berdasarkan koefisien persamaan tersebut (bi; angka mutlak), maka peranan masing-masing sifat hardboard (Yi) tak sama terhadap nilai urutan mutu yaitu $\mathrm{Y} 4>\mathrm{Y} 3>\mathrm{Y} 1>\mathrm{Y} 5>\mathrm{Y} 8>\mathrm{Y} 9>\mathrm{Y} 7>\mathrm{Y} 2>\mathrm{Y} 6$.

Dari persamaan diskriminan tersebut diperoleh indikasi (Tabel 5) bahwa untuk hardboard yang dibentuk dari masing-masing individu serat (bentuk pulp, 100\%) ternyata rumput gelagah paling berprospek, dengan nilai diskriminan $($ Ydiskr $=93,2-143,1)$; disusul oleh pulp TKKS $($ Ydiskr $=88,7-130,2)$ dan pulp bambu (Ydiskr $=$ 80,4-121,9). Ini mengindikasikan bahwa aspek positif sifat dasar dan sifat pengolahan pulp rumput gelagah (antara lain kandungan ekstraktif baik polar maupun kurang polar yang tinggi, daya tenun serat tinggi, berat jenis rendah, dan derajat kehalusan pulp awal rendah) mendominasi aspek negatifnya (a.l. kadar air tinggi, kadar selulosa rendah, konsumsi alkali tinggi, dan rendemen pulp rendah) (Tabel 1, 2 dan 3). Untuk TKKS, yang menempati urutan kedua sesudah rumput gelagah, diduga aspek negatifnya yang menonjol adalah masih tingginya kandungan sisa minyak/lemak (diindikasikan pada konsumsi alkalinya tinggi) dan selanjutnya memperkuat dugaan berpengaruh negatif pada sifat kekuatan hardboard.Untuk bambu dengan urutan nilai diskriminan paling rendah, ini diduga karena aspek negatifnya yang banyak berperan seperti berat jenis, bilangan Runkel, dan koefisien kekakuan serat yang tinggi; dan derajat kehalusan pulp awal tinggi) (Tabel 1, 2, dan 3). Untuk harboard yang dibentuk dari campuran macam- macam bahan serat, nilai diskriminan tertinggi adalah dari campuran 50\% pulp rumput gelagah $+50 \%$ pulp TKKS (Ydiskr $=91,51-136,91$ ), dan terendah adalah campuran $50 \%$ pulp TKKS $+50 \%$ pulp bambu (Yidkr $=85,013-126,047)$. Ternyata nilai diskriminan dengan urutan ke satu, dua, dan tiga adalah yang melibatkan pulp RG; sedangkan nilai dengan urutan terendah (ke empat) adalah yang tak melibatkan pulp RG, tetapi melibatkan pulp bambu. Ini memperkuat indikasi telaahan urutan nilai diksriminan bahan serat secara individu, di mana urutannya adalah pulp RG, pulp TKKS, dan pulp bambu.

Nilai diskriminan telaahan pengaruh konsentrasi alkali (Lampiran 1) menunjukkan bahwa nilai diskriminan pada konsentrasi 10,5 $\%(Y$ diskr $=109,2-143,1)$ ternyata lebih tinggi dibandingkan nilai pada konsentrasi 9\% (Ydiskr $=80,4-119,2$ ). Ini berindikasi bahwa aspek positif akibat peningkatan konsentrasi alkali (a.l. derajat kehalusan pulp awal lebih rendah, waktu giling lebih singkat, dan kerapatan/sifat kekuatan hardboard meningkat) mendominir aspek negatifnya (a.l. konsumsi alkali lebih tinggi, rendemen pulp lebih rendah, dan kestabilan dimensi hardboard menurun) (Tabel 1, 2, dan 3; dan Lampiran 1). Selanjutnya Untuk penggunaan aditif (perekat TF), ternyata nilai diskriminan harboard dengan perekat TF (Ydiskr $=116,509$ 143,1) lebih tinggi dibandingkan kontrol/tanpaperekat $(\mathrm{Y}$ diskr $=85,013-97,943) . \quad$ Ini dapat dimaklumi karena penggunaan aditif memang berperan positif terhadap sifat fisis/kekuatan hardboard (a.l. kadar air dan penyerapan air turun, dan kerapatan/kestabilan dimensi/sifat kekuatan meningkat, meski ketahanan panas menurun).

Hasil analisis diskriminan secara menyeluruh berindikasi kuat bahwa produk hardboad yang paling banyak memenuhi persyaratan JIS dan ISO adalah yang dibentuk dari $100 \%$ RG (bentuk pulp) dengan penggunaan perekat $\mathrm{TF}$ pada konsentrasi alkali 9-10,5\% (Ydiskr=137,4-143,1). Meskipun demikian, TKKS dan bambu (keduanya dalam bentuk pulp) tetap bisa prospektifuntuk hardboard melalui pencampurannya dengan pulp RG pada proporsi berturut-turut $50 \%$ pulp RG + $50 \%$ pulp TKKS $($ Ydiskr $=136,91) ; 50 \%$ pulp $\mathrm{RG}+50 \%$ pulp bambu (Ydiskr $=132,506)$; dan $33,33 \%$ pulp $\mathrm{RG}+33,33 \%$ pulp TKKS $+33,33 \%$ pulp bambu $($ Ydiskr $=131,689)$, keseluruhannya dengan perekat TF dan pada konsentrasi alkali $10,5 \%)$. 
Tabel 5. Nilai Y-Diskr terhadap Bahan Baku Serat pada masing-masing Proporsi

\begin{tabular}{clcc}
\hline No & \multicolumn{1}{c}{ Bahan Baku } & Proporsi & Y diskr \\
\hline A & Serat individu & & \\
\hline 1 & RG & $100+0+0$ & $93,4-143,1$ \\
2 & TKKS & $0+100+0$ & $88,7-130,2$ \\
3 & Bambu & $0+0+100$ & $80,4-121,9$ \\
\hline B & Campuran serat & & \\
\hline 4 & RG+TKKS & $50+50+0$ & $91,51-136,91$ \\
5 & RG+Bambu & $50+0+50$ & $86,721-132,50$ \\
6 & TKKS+Bambu & $50+0+50$ & $85,013-126,04$ \\
7 & RG+TKKS+Bambu & $33+33+33$ & $87,491-131,68$ \\
\hline
\end{tabular}

Supaya dapat lebih memenuhi syarat JIS dan ISO (mencapai atau mendekati 100\%), pada individu serat pulp (RG) atau proporsi campurannya tersebut, disarankan antara lain penggunaan cross-linking agent dan water repellent (Santoso, 2011). Untuk memanfaatkan serat TKKS $100 \%$, perlu digunakan pemasakan dengan konsentrasi alkali $>10,5 \%$, guna lebih banyakmelarutkan minyak/lemakyangterindikasi kuat berpengaruh negatif terhadap sifat kekuatan produk hardboard dan menimbulkan noda berwarna gelap pada permukaannya. Diharapkan pula usaha tersebut meningkatkan prospek pemanfaaatan serat TKKS secara individu $(100 \%)$ atau secara campurannya dengan bahan serat lain (RG dan bambu) untuk hardboard. Hasil analisis ini menunjukkan sifat-sifat yang memerlukan perbaikan, dengan urutan prioritas MOR, diikuti oleh MOE, kerapatan, IB, daya hantar panas, ketahanan panas, pengembangan tebal, kadar air, dan akhirnya penyerapan air.

\section{Pencermatan Skala Nano}

Pencermatan tersebut menggunakan alat XRD menunjukan bahwa kristalinitas serat RG adalah urutan kedua setelah serat bambu. (Tabel 6). Hal ini berperan positif terhadap kekuatan individu serat RG (Smook, 2002; Santoso, 2011), dan ikut menjelaskan tingginya sifat kekuatan hardboard yang dibentuk dari $100 \%$ pulp RG atau dari campuran bahan serat dimana pulp RG dilibatkan dalam campuran tersebut.

Meskipun kristalinitas serat bambu paling tinggi (indikasi kekuatan individu serat tersebut tinggi); diduga karena tingginya kadar lignin bambu, dinding seratnya yang tebal dan koefisien kekakuannya tinggi (keseluruhannya mengakibatkan seratnya sukar menggepeng dan kurang fleksibel) sehingga berpengaruh negatif terhadap ikatan dan anyaman antar serat selama pembentukan lembaran hardboard, dan selanjutnya berakibat lebih rendahnya sifat kekuatan hardboard yang dibentuk dari 100\% pulp bambu (Tabel 1, 2, 3). Kristalinitas TKKS yang rendah (Tabel 6), dan adanya sisa minyak/ lemak juga berakibat lebih rendahnya sifat kekuatan tersebut dibandingkan dari 100\% pulp RG. Adanya sisa lemak/minyak bisa mengganggu ikatan/anyaman antar serat. Meskipun demikian, lebih tingginya sifat kekuatan hardboard dari $100 \%$ pulp TKKS dibandingkan dari 100\% pulp bambu, diduga terkait dengan lebih mudahnya pulp TKKS tersebut digiling untuk mencapai derajat kehalusan 600-700 mL CSF (Tabel 2). Pulp yang mudah digiling berindikasi tingkat fibrilisasi dan hidrasi serat tinggi, dan ini berpengaruh positif pula pada ikatan/anyaman antar serat dan akhirnya sifat kekuatan hardboard (Casey, 1980).

Tabel 6. Kristalinitas Bahan Serat ${ }^{*}$

\begin{tabular}{clc}
\hline No & \multicolumn{1}{c}{ Macam Bahan Serat } & $\begin{array}{c}\text { Kristalinitas } \\
\%\end{array}$ \\
\hline 1 & Rumput gelagah & 32,93 \\
2 & Tandan kosong kelapa sawit & 27,44 \\
3 & Bambu & 35,27 \\
\hline Nilai rata-rata
\end{tabular}

\section{Kemungkinan Penerapan Hasil Percobaan Hardboard untuk Usaha Kecil Menengah}

Pembuatan papan serat (hardboard) pada percobaan ini (menggunakan serat alternatif yaitu rumput gelagah, TKKS, dan bambu) diawali 
dengan pemasakan (pulping) dengan proses semi-kimia soda panas terbuka, dilanjutkan dengan pembentukan lembaran cara basah. Bahan kimia pada proses tersebut bersifat tunggal $(\mathrm{NaOH})$, yang berfungsi hanya melunakkan atau melarutkan lignin secara parsial sehingga seratserat yang saling berikatan satu sama lainnya pada proses mekanis selanjutnya (beating/refining) tercerai berai menjadi serat terpisah pulp.

Pada pengolahan pulp semi-kimia ini menggunakan sistim terbuka, jadi pada penerapan komersial sistim/peralatannnya diperkirakan tidak terlalu rumit dan tidak banyak memerlukan biaya dibandingkan dengan yang tertutup. Konsumsi alkali pada pengolahan pulp ini berkisar sekitar 8899\% (relatif besar karena mendekati 100\%). Sekiranya sisa bahan kimia pemasak (alkali) didaur ulang akan memerlukan biaya besar, dibandingkan tanpa daur ulang.

Pembentukan lembaran papan serat (hardboard) pada percobaan ini menggunakan cara basah. Di samping pembentukan cara basah, terdapat cara kering (Suchsland and Woodson, 1986). Cara basah memiliki keunngulan yaitu membutuhkan aditif lebih sedikit (khususnya perekat) karena pada proses basah terdapat lignin yang dapat berfungsi sebagai perekat alami, dan peralatan/biaya operasi yang diperlukan lebih murah. Cara basah, tanpa dilakukannya daur ulang bahan kimia, dan penerapan pengolahan pulp dengan sistim terbuka memungkinkan penerapan komersial pembuatan harboard ini lebih sesuai untuk usaha kecil menengah (UKM).

\section{KESIMPULAN DAN SARAN}

Dari 3 macam bahan serat secara individu (rumput gelagah/RG, tandan kosong kelapa sawit/TKKS, dan bambu), menunjukkan RG $(100 \%)$ paling berprospek, dengan urutan ke dua dan ketiga berturut-turut pulp TKKS (100\%) dan pulp bambu (100\%).

Dalam bentuk campuran serat untuk hardboard, proporsi yang paling berprospek adalah campuran $50 \%$ pulp RG $+50 \%$ pulp TKKS, diikuti oleh proporsi lain hingga prospek terendah yaitu campuran 50\% pulp RG $+50 \%$ pulp TKKS, $50 \%$ pulp RG $+50 \%$ pulp bambu, $33.33 \%$ pulp $\mathrm{RG}+33.33 \%$ pulp TKKS $+33.33 \%$ pulp bambu, dan akhirnya $50 \%$ pulp TKKS $+50 \%$ pulp bambu. Peningkatan konsentrasi alkali dan penggunaan perekat tanin formaldehida berperan positif terhadap sifat kekuatan (mekanis) produk hardboard. Hardboard yang dibentuk dari $100 \%$ pulp RG, pada konsentrasi alkali $10,5 \%$, dan menggunakan perekat TF paling banyak memenuhi persyaratan JIS dan ISO, sehingga paling berprospek untuk hardboard.

Agar hardboard dari bahan serat yang diteliti (RG, TKKS, dan bambu) bisa lebih memenuhi persyaratan (JIS dan ISO), disarankan penggunaan aditif berupa cross-linking agent dan water repellent.

Guna memperbaiki mutu/kualitas harboard hasil percobaan, perlu usaha untuk memperbaiki sifatnya dengan urutan prioritas mula-mula MOR, lalu MOE, kerapatan, IB, daya hantar panas, ketahanan panas, pengembangan tebal, kadar air, dan akhirnya penyerapan air.

Percobaan pembuatan hardboard berbahan baku serat alternatif ( $R G$, TKKS, dan bambu) dengan hasil prospektif diharapkan dapat mengurangi ketergantungan pada bahan serat konvensional (terutama kayu hutan alam).

Pembentukan lembaran papan serat dengan cara basah memerlukan lebih sedikit bahan aditif dan biaya operasi lebih rendah. Ini memungkinkan keseluruhan operasi pembuatan papan serat untuk usaha kecil menengah (UKM). Secara keseluruhan mengurangi ketergantungan pada serat konvensional dan diharapkan ikut berperan pula melestarikan sumber daya alam, dengan operasi UKM berkelanjutan.

\section{DAFTAR PUSTAKA}

Alamsyah R, O Afandi, Batubara, R., 2013. Analisis potensi ketersediaan dan pemasaran bambu belangke (Gigantochloa pruriens Widjaja) di hutan rakyat bambu desa timbang lawan Kecamatan Bahorok Kabupaten Langkat dalam industri dupa bambu. Peronema Forestry Science, 2(2), 137-142.

Anonim. 2012. Saccharum spontaneum. Website: http://en.wikipedia.org/wiki/Saccharum spontaneum. Diakses pada 8 July 2012

ANSI Standards, A208.2-1994. (1994). Medium Density Fiberboards (MDF). National Particleboard Association, Gaithersburg, MD.

Apriani, Y. (2010). Kemungkinan pemanfaatan kayu mahang sebagai bahan baku alternatif untuk pulp yertas. Buletin Hasil Hutan, 16 (2), 141-149. 
Badan Pusat Statistik. 2013. Statistik Indonesia 2012. Jakarta.

Bertaud F., Lingua, S. T., Pizzi, A., Navarrete, P., Conil, M.P., 2012. Development of green adhesives for fiberboard manufacturing, using tannins and lignin from pulp mill residues. Cellulose Chem. Technology, 4(78), 449-455.

Browning BL. 1967. Viscosity and molecular weight. dalam Methods of wood chemistry, Vol. 2. B. L. Browning ed., Interscience Publishers, New York, Ch. 25, 519-557.

Casey, J.P. 1980. Pulp and Paper Chemistry and Techology. Third edition, Vol. I. A Wiley-Interscience Publication. New York Brisbane - Toronto.

Forest Watch Indonesia. 2013. Potret keadaan hutan indonesia periode 2009-2013. http:// fwi.or.id/publikasi/potret-keadaan-hutanindonesia-periode-2009-2013/, daiakses 14 Juli 2015.

Hayati A, 2011. MDF pulp kraft rendemen tinggi dari tanaman kembang sepatu. Skripsi. Departmen Hasil Hutan, Fakultas Kehutanan, Institut Pertanian Bogor.

Indrawan, D.A., Roliadi, H., Tampubolon, R.M., Pari G., 2013. Penyempurnaan sifat papan serat kerapatan sedang (MDF) dari pelepah nipah dan campurannya dengan sabut kelapa. Jurnal Penelitian Hasil Hutan, vol. 31 (2): 120-140.

Indrawan, D.A., Roliadi, H., Tampubolon, R.M., Pari, G., Santoso, A., 2013. Teknologi Pembuatan Papan Serat Tipe Hardboard. Laporan Hasil Penelitian. P3KKPHH. Bogor

ISO.2013. ISO/DIS 27769-2, Wood-based panels - Wet process fiberboard, part 1: Specification; and ISO/DIS 16895-2, Wood based panels - Dry process fiberboard: Requirements. SC/TC 89/SC1. Geneva, Switzerland.

JIS A 5905.2003. Japanese Industrial Standard (JIS): Fiberboard.Tokyo, Japan.

Laksono, H., 2008. Kelarutan komponen kimia kayu reaksi melinjo (Gnetum gnemon L.) selama proses pulping kraft. Skripsi. Departemen Hasil Hutan, Fakultas Kehutanan, Institut Pertanian Bogor.

Mancera C., Mansouri, N.E.E., Vilaseca, F., Ferrando, F., Salvado, J., 2011. The effect of lignin as natural adhesive on the physicomechanical properties of Vitis vinifera fiberboards. BioResources, 6(3), 2851-2860.

Meyer, B.S., Anderson, D.B., Bohning, R.H., 1985. Introduction to Plant Physiology. D. van Nostrand Co., Inc. Totonto - London New York.
Narwin. 2012.Rumput gelagah yang belum termanfaatkan. http://melung.desa. id/2012/10/30/rumput-gelagah-yang-belumtermanfaatkan/, diakses 13Juli 2015.

Purwito. 2012. Produk dari bambu dan turunannya. Bahan Presentasi Workshop Rekonstruksi Topic Bumi Village, Sanggar Kreatif Anak Bangsa, 11 Juli 2012, Ciputat, Tangerang Selatan.https://bamboeindonesia. wordpress.com/peneliti-bambu/purwito/ makalah/, diakses 13 Juli 2015.

Roliadi, H., Anggraini, D., Pari, G., Tampubolon, R.M., 2012. Teknologi pembuatan papan serat: Penyempurnaan sifat papan serat tipe MDF dari nipah dan campurannya dengan sabut kelapa. Laporan Hasil Penelitian Tahun 2012. Pusat Litbang Keteknikan Kehutanan dan Pengolahan Hasil Hutan, Bogor.

Santoso, A. 2011. Tanin dan lignin dari Acacia mangium Willd. Sebagai bahan perekat kayu majemuk masa depan. Orasi Pengukuhan Profesor Riset, Bidang Pengolahan Hasil Hutan pada 25 Oktober 2011 di Jakarta. Badan Penelitian Pengembangan Kehutanan, Kementerian Kehutanan. Jakarta.

Saputro, D.D., Widayat, W., Rusiyanto, Saptoadi, H, Fauzun. 2012. Karakterisasi briket dari limbah pengolahan kayu sengon dengan metode cetak panas. Prosiding Seminar Nasional Aplikasi Sains \& Teknologi (SNAST) Periode III. Yogyakarta, 3 November 2012.

SAS. 2007. SAS (Statistical Analysis System) Guide for Personal Computers, Version 6 Edition. SAS Institute Inc. Cary, NC. $27512-8000$

Saupe. S.G. 2011. Lectures Notes and Materials for Plant Physiology. http://employees. csbsju.edu/ssaupe/biol327/lecture-home. htm. Diakses: 11 Juli 2013.

Silitonga, T., R.M. Siagian, dan A. Nurachman. 1972. Cara pengukuran dimensi serat kayu dan bahan berligno-selulosa lain di Lembaga Penelitian Hasil Hutan (LPHH). Publikasi khusus No. 12. LPHH. Bogor.

Sjostrom, E. $2002 . \quad$ Wood Chemistry: Fundamentals and Applications. Academic Press. New York - London - Tokyo - Toronto.

Smook, G.A. 2002. Handbook for Pulp and Paper Technologists. Joint Textbook Committee of the Paper Industry.Atllanta, Georgia

Suchsland, O., Woodson., G.E., 1986. Fiberboard manufacturing practices in the United States. USDA - Forest Service Agricultutal Handbook No. 640. 
Syamsu, K., Roliadi, H., Candra, K.P., Arsyad, A.J., 2014. Kajian proses produksi pulp dan kertas ramah lingkungan dari sabut kelapa. Jurnal Teknologi Pertanian Universitas Mulawarman, 9(1), 16-25.

TAPPI. 2007. Technical Association of the Pulp and Paper Industry (TAPPI)'s Test Methods. TAPPI Press.Atlanta, Georgia.

The President Post. 2013. Potensi besar, industri bambu Indonesia patut dikembangkan. http:// thepresidentpostindonesia.com/2013/12/01/ potensi-besar-industri-bambu-indonesiapatut-dikembangkan/, diakses 13 Juli 2015.
Wardani, A.P.K., Widiawati, D., 2014. Pemanfaatan tandan kosong kelapa sawit sebagai material tekstil dengan pewarna alam untuk produk kriya. Jurnal Tingkat Sarjana Bidang Senirupa dan Desain, 1, 1-9.

Wibisono I, H Leonardo, Antaresti \& Aylianawati. 2011. Pembuatan Pulp dari alang-alang. Widya Teknik, 10(1), 11-20. 